Atomic Force Microscope (AFM) measurements and analysis on Sagem 05R0025 secondary substrate

R. Soufli, S. L. Baker, J. C. Robinson

May 24, 2006 
This document was prepared as an account of work sponsored by an agency of the United States Government. Neither the United States Government nor the University of California nor any of their employees, makes any warranty, express or implied, or assumes any legal liability or responsibility for the accuracy, completeness, or usefulness of any information, apparatus, product, or process disclosed, or represents that its use would not infringe privately owned rights. Reference herein to any specific commercial product, process, or service by trade name, trademark, manufacturer, or otherwise, does not necessarily constitute or imply its endorsement, recommendation, or favoring by the United States Government or the University of California. The views and opinions of authors expressed herein do not necessarily state or reflect those of the United States Government or the University of California, and shall not be used for advertising or product endorsement purposes.

This work was performed under the auspices of the U.S. Department of Energy by University of California, Lawrence Livermore National Laboratory under Contract W-7405-Eng-48. 


\section{Atomic Force Mieroscope (AFM) measurements and analysis on Sagem 0520025 secondary substrate}

Regina Souili, Sherry Baker, and Jefi C. Robinson Januane 17.2006 


\section{Map of AFM measurement locations on Sagem 05R0025 secondary}

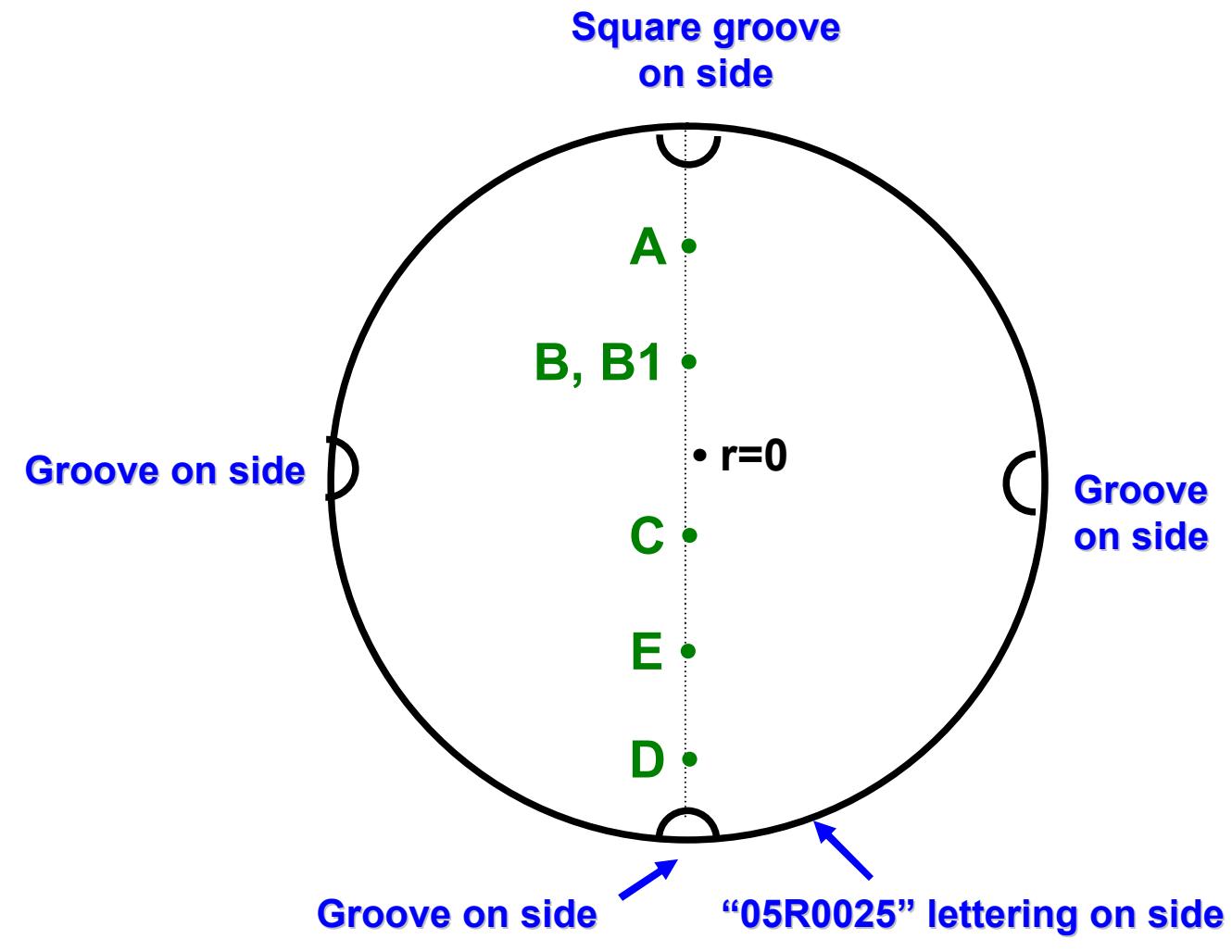

\begin{tabular}{|c|c|}
\hline Location & $\begin{array}{c}\text { Radius } r \\
\text { from mirror } \\
\text { center }(\mathrm{mm})\end{array}$ \\
\hline A & 25 \\
\hline B & 18 \\
\hline C & 13 \\
\hline D & 32 \\
\hline E & 22 \\
\hline
\end{tabular}




\section{AFM images from Sagem 05R0025 secondary}

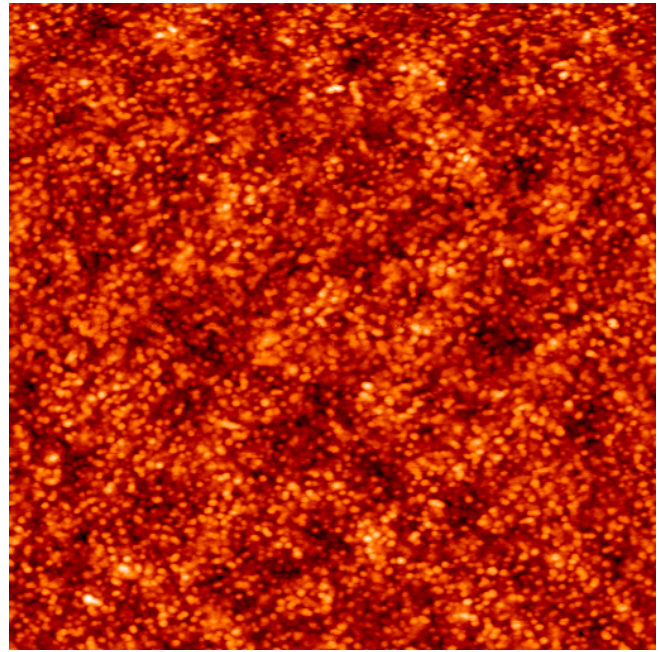

$2 \times 2 \mu \mathrm{m}^{2}$, loc. $A$

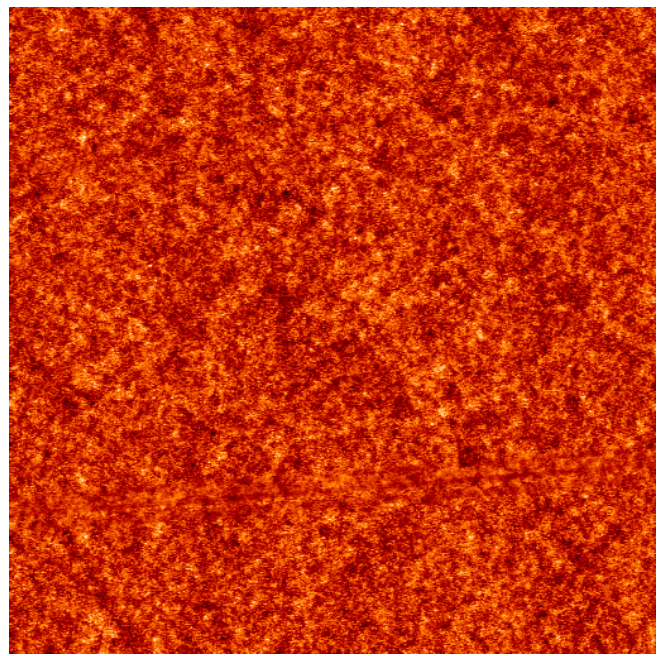

$10 \times 10 \mu \mathrm{m}^{2}$, loc. $A$

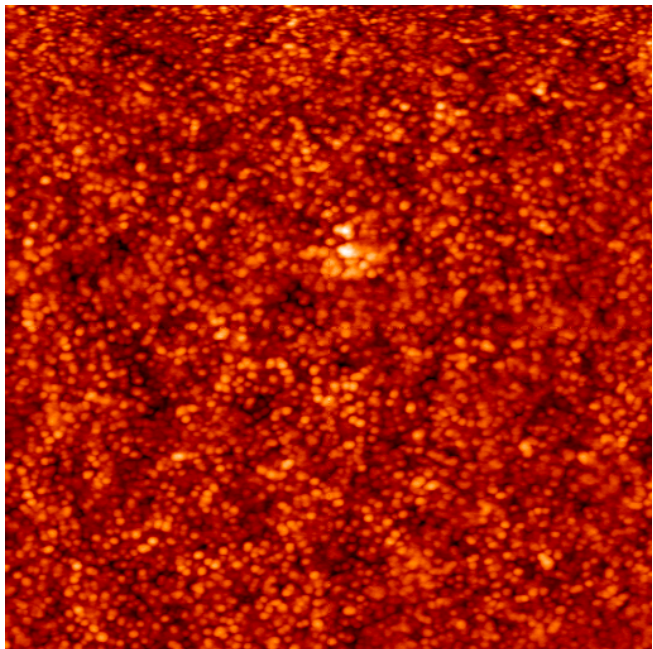

$2 \times 2 \mu \mathrm{m}^{2}$, loc. B

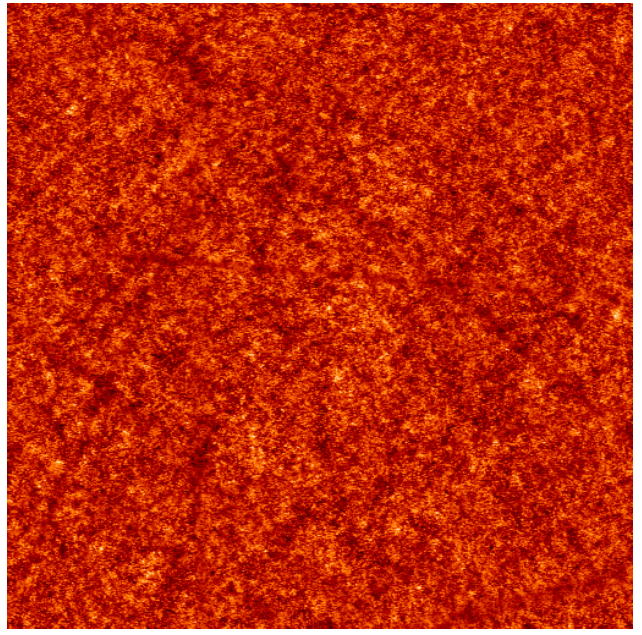

$10 \times 10 \mu \mathrm{m}^{2}$, loc. $B$

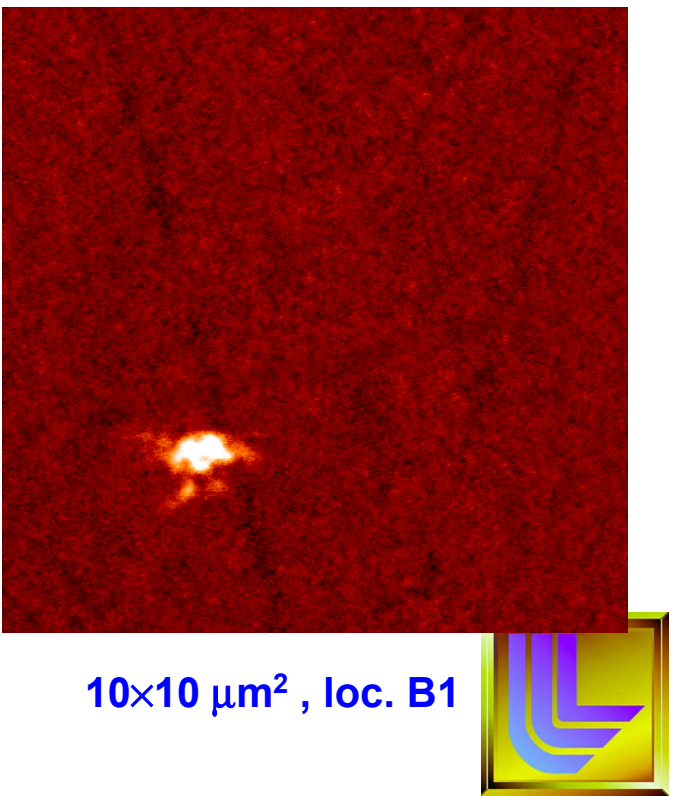

Regina Soufli et al, 01/17//06 


\section{AFM images from Sagem $05 R 0025$ secondary}

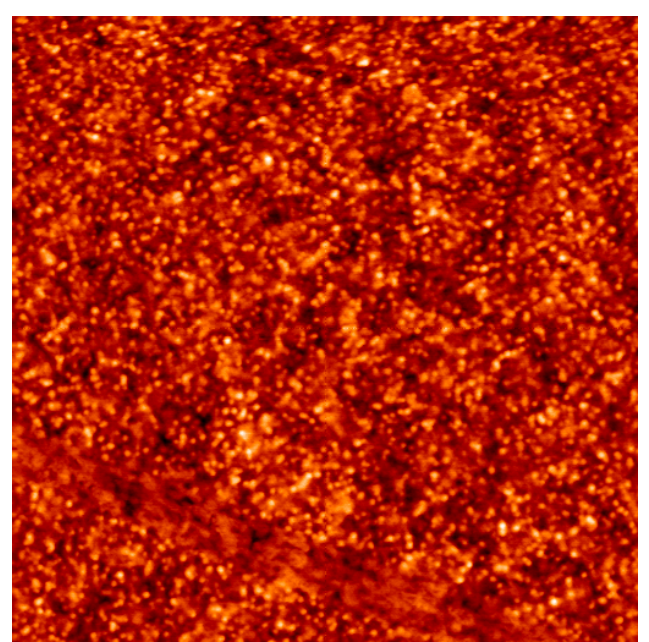

$2 \times 2 \mu \mathrm{m}^{2}$, loc. $\mathrm{C}$

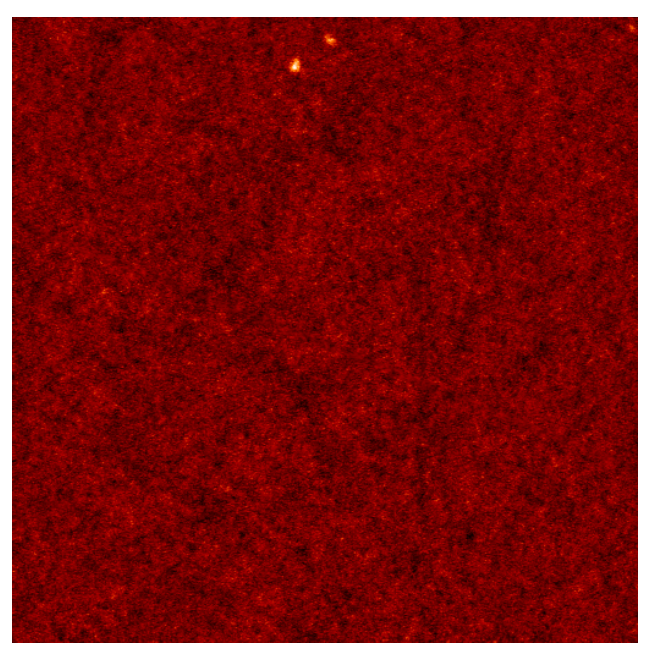

$10 \times 10 \mu \mathrm{m}^{2}$, loc. $\mathrm{C}$

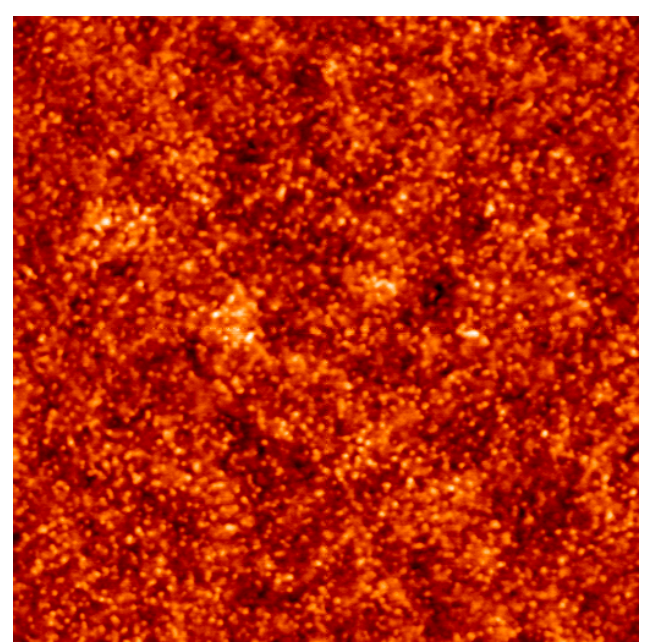

$2 \times 2 \mu \mathrm{m}^{2}$, loc. D

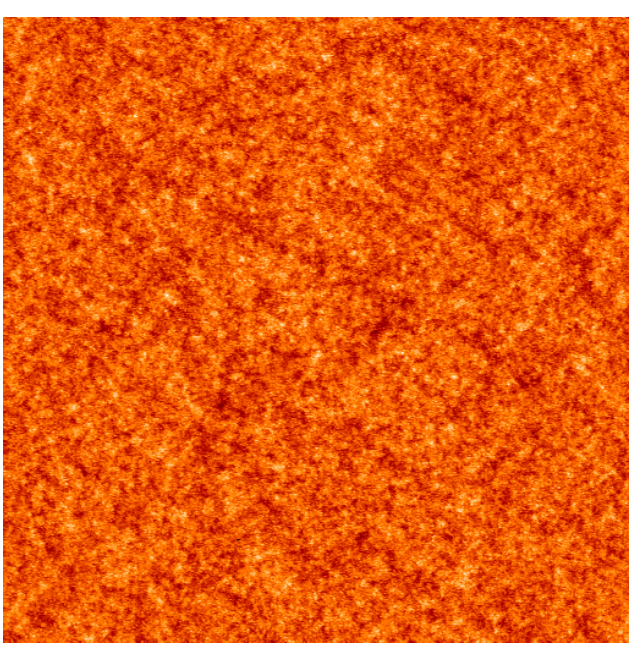

$10 \times 10 \mu \mathrm{m}^{2}$, loc. $\mathrm{D}$

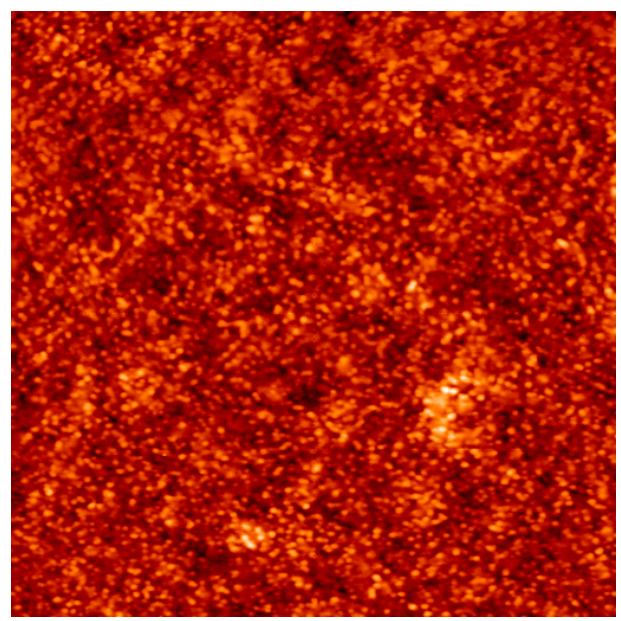

$2 \times 2 \mu \mathrm{m}^{2}$, loc. $\mathrm{E}$

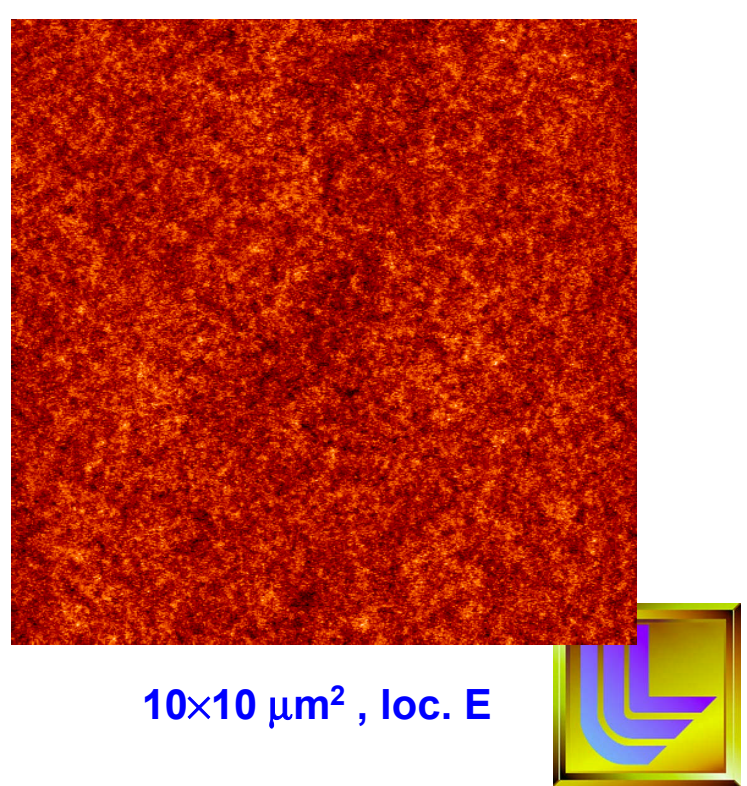




\section{Power Spectral Density (PSD) analysis of AFM data from Sagem 05R0025 secondary substrate}

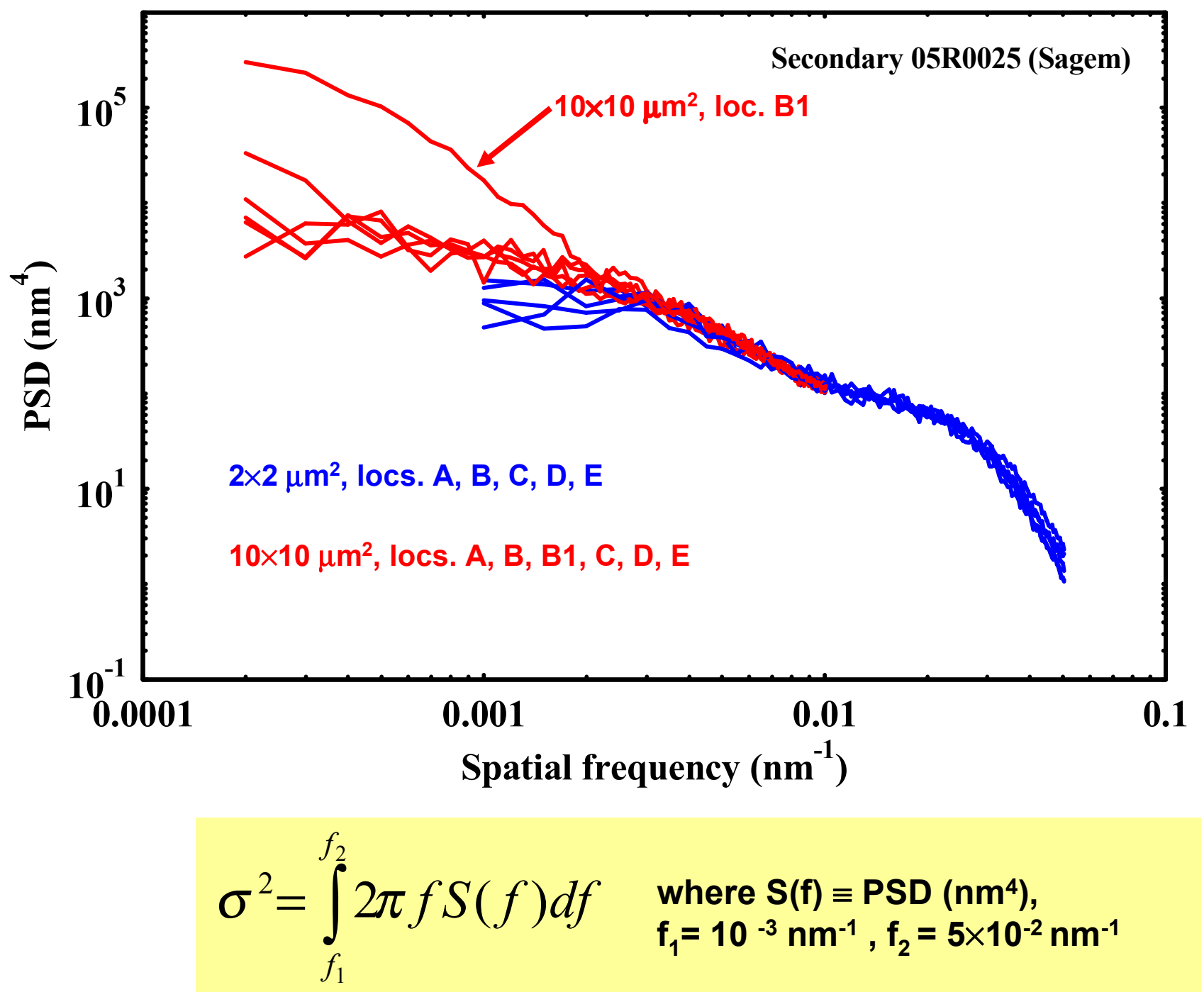

\begin{tabular}{|c|c|}
\hline Location & $\sigma(\mathrm{nm})$ \\
\hline A & 0.55 \\
\hline B & 0.54 \\
\hline C & 0.51 \\
\hline D & 0.54 \\
\hline E & 0.54 \\
\hline
\end{tabular}


2D PSD image vs. spatial frequency of $10 \times 10 \mu \mathrm{m}^{2}$ AFM scan from Sagem 05R0025 secondary substrate

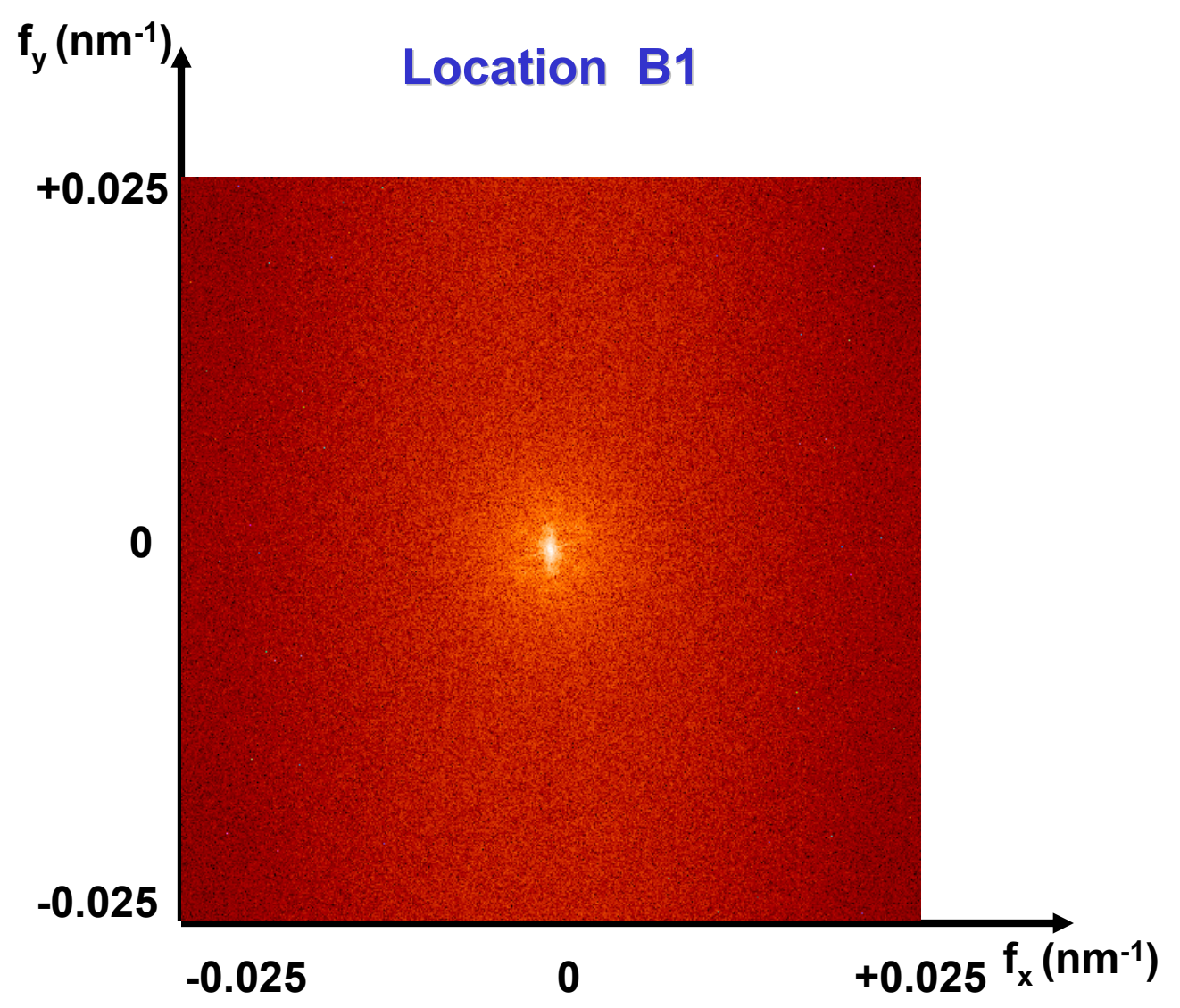




\section{Summary of AFM on Sagem 05R0025 secondary substrate}

$>2 \times 2 \mu \mathrm{m}^{2}$ and $10 \times 10 \mu \mathrm{m}^{2}$ AFM measurements and analysis on Sagem 05R0025 secondary substrate at LLNL indicate rather uniform and extremely isotropic finish across the surface, with high-spatial frequency roughness $\sigma$ in the range $5.1-5.5 \AA \mathrm{rms}$

$>$ The marked absence of pronounced long-range polishing marks in any direction, combined with increased roughness in the very high spatial frequencies, are consistent with ion-beam polishing treatment on the surface. These observations are consistent with all earlier mirrors we measured from the same vendor.

$>$ All data were obtained with a Digital Instruments Dimension 5000TM atomic force microscope

$>$ Special thanks to D.L. Windt for crucial updates to the TOPO software for AFM data analysis

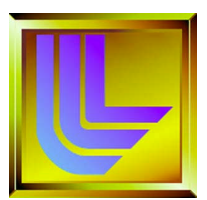

